\title{
Severe hypotension and water intoxication developed after an accidental oxytocin overdose in a morbidly obese patient undergoing cesarean section
} -A case report-

\author{
Jang Hyeok In, Jin Woo Choi, Hong Soo Jung, Jung-Ah Lee, Jin-Deok Joo, Dae-Woo Kim, Yeon Soo Jeon, \\ and Ju-Seon Park
}

Department of Anesthesiology and Pain Medicine, St. Vincent Hospital, Catholic University of Korea, Suwon, Korea

We present a 32-year-old, extremely obese, pregnant woman who developed severe hypotension and water intoxication after an accidental injection of large bolus of oxytocin during cesarean section under general anesthesia. The patient was initially thought to have an amniotic fluid embolism because of the abrupt hemodynamic changes developed immediately after fetal delivery and lack of recognition of medication error. It is highly recommended that careful attention should be paid not only to the possibility of hemodynamic deterioration and water intoxication if oxytocin is given rapidly in excessive doses, but to the confirmation of the proper use of the drug before it is injected. (Korean J Anesthesiol 2011; 60: 290-293)

Key Words: Oxytocin, Water intoxication.

Oxytocin is best known for its contractile activity on uterine smooth muscle, and thus is still widely used to reduce uterine bleeding after delivery of the fetus. However, oxytocin when given in rapid bolus produces marked but shortlived hypotension and tachycardia [1-3]. Sometimes, this abrupt and severe hemodynamic depression may need to be distinguished from placental abruption, acute myocardial infarction, or a pulmonary embolism in patients undergoing delivery. Therefore, it is recommended to administer a dose of 5 international units of oxytocin by slow intravenous injection rather than a rapid bolus injection [1]. In addition, oxytocin may cause water intoxication via an anti-diuretic hormone-like activity when administered in excessive dose with electrolytefree solution [4]. We report a case of 32-year-old, extremely obese, pregnant woman in which an inadvertent rapid injection of large bolus of oxytocin led to cardiovascular collapse initially and water intoxication later during the Cesarean delivery. In our case, early catastrophic event was regarded as an amniotic fluid embolism (AFE) because of the characteristic signs, including abrupt hemodynamic changes and respiratory distress [5].

Received: September 6, 2010. Revised: November 10, 2010. Accepted: November 23, 2010.

Corresponding author: Yeon Soo Jeon, M.D., Department of Anesthesiology and Pain Medicine, St. Vincent Hospital, Catholic University of Korea, 93-6, Ji-dong, Paldal-gu, Suwon 422-723, Korea. Tel: 82-31-249-7114, Fax: 82-31-258-4212, E-mail: ijangh@naver.com

(c) This is an open-access article distributed under the terms of the Creative Commons Attribution Non-Commercial License (http:// creativecommons.org/licenses/by-nc/3.0/), which permits unrestricted non-commercial use, distribution, and reproduction in any medium, provided the original work is properly cited. 


\section{Case Report}

A 32-year-old multipara at 40 weeks' gestation was scheduled for elective cesarean section due to cephalopelvic disproportion under general anesthesia. She weighed $140 \mathrm{~kg}$ and was $161 \mathrm{~cm}$ in height, and thus the body mass index (BMI) was $54.0 \mathrm{~kg} / \mathrm{m}^{2}$. Her medical history and laboratory data were unremarkable. On arrival in the operating room, her blood pressure and pulse rate were 152/98 $\mathrm{mmHg}$ and 87 beats/min, respectively and percutaneous oxygen saturation was $94 \%$ on room air. Anesthesia was induced with intravenous thiopental sodium $500 \mathrm{mg}$, succinylcholine $100 \mathrm{mg}$, and vecuronium $8 \mathrm{mg}$, and maintained with 1.2 vol\% sevoflurane (inspired) until the fetal delivery and $1-3$ vol\% sevoflurane (inspired) thereafter in $50 \%$ nitrous oxide after tracheal intubation. The patient was mechanically ventilated at a tidal volume of $8 \mathrm{ml} / \mathrm{kg}$, and the rate was adjusted to maintain the end-tidal carbon dioxide tension around $35 \mathrm{mmHg}$ and oxygen saturation rose to $98 \%$. The cesarean section was performed through a low midline incision and a $3.12 \mathrm{~kg}$ male was delivered $15 \mathrm{~min}$ after anesthetic induction. The Apgar scores were 8 at $1 \mathrm{~min}$, and 9 at $5 \mathrm{~min}$. Immediately after placental delivery, a bolus dose of 5 units oxytocin, carbetocin $100 \mu$ g, midazolam $4 \mathrm{mg}$ followed by a continuous infusion of 25 units of oxytocin (Yuhan corp., Seoul, Korea) mixed in $1 \mathrm{~L}$ of Hartmann's solution was ordered to be given. Within a few min after their injections, her heart rate increased above 130 beats/min and arterial blood pressure decreased to $68 / 34 \mathrm{mmHg}$. Intravenous ephedrine $10 \mathrm{mg}$ was given immediately followed by continuous infusion of dopamine $8-10 \mu \mathrm{g} / \mathrm{kg} / \mathrm{min}$ with rapid administration of Hartman's and colloid solution (Voluven, Fresenius Kabi, Germanry). Thereafter systolic blood pressure increased up to $90 \mathrm{mmHg}$; however, her oxygen saturation gradually decreased to $82 \%$, while the end-tidal carbon dioxide tension remained unchanged. We promptly discontinued the nitrous oxide, increased the $\mathrm{FiO}_{2}$ to 1.0, and changed her position from the Trendelenburg to the supine. The trachea was cleared several times because the breathing sounds were not clear with wheezing. The patient was given dexamethasone $10 \mathrm{mg}$ and aminophylline $150 \mathrm{mg}$ intravenously followed by a continuous infusion of aminophylline $350 \mathrm{mg}$ mixed in $500 \mathrm{ml}$ of $5 \%$ dextrose water. Her oxygen saturation increased to $89 \%$ at the time when the surgical procedure was completed.

We initially regarded the deterioration of hemodynamics as an amniotic fluid embolism (AFE), but could not confirm the diagnosis because the signs of a coagulopathy, including hemorrhage, disseminated intravascular coagulation, or inadequate uterine contractions, were lacking. It was also difficult to rule out an AFE because we could not obtain any blood sample for laboratory testing of AFE until the end of the surgery. All attempts to access the peripheral and central veins or even arteries were failed because of the patient's short, fatty neck and the peripheral vessels were not visible due to morbid obesity.

It was then revealed that 25 units of oxytocin were inadvertently administered as a single bolus simultaneously with 5 units of oxytocin and carbetocin $100 \mu \mathrm{g}$ instead of mixed with Hartman's solution. Until that time, 1.0 L of Hartman's solution and $500 \mathrm{ml}$ of colloid solution had already been infused. To prevent the development of water intoxication due to oxytocin, Hartman's solution was exchanged with $0.9 \%$ normal saline and lasix $20 \mathrm{mg}$ and $25 \%$ mannitol $12.5 \mathrm{~g}$ were intravenously administered. Upon completion of surgery, a central venous catheter was inserted through the right femoral vein to withdraw blood for measurements of plasma electrolytes and coagulation profiles and to administer drugs and fluids. The plasma $\mathrm{Na}^{+}$and $\mathrm{K}^{+}$concentrations measured just before the end of anesthesia were 118 and $3.9 \mathrm{mmol} / \mathrm{L}$, respectively, and thus lasix $20 \mathrm{mg}$ was additionally administered intravenously in an attempt to treat the water intoxication. There was no evidence of coagulopathy with the normal coagulation profiles, including the activated prothrombin time (20.9 sec), fibrinogen $(324.1 \mathrm{mg} / \mathrm{dl})$, platelet count $\left(329 \times 10^{9} / \mathrm{L}\right)$, and fibrinogen degradation products (FDP; $10.5 \mu \mathrm{g} / \mathrm{ml}$ ). The estimated blood loss, amount of fluid infused, and volume of urine during the operation were $1,000 \mathrm{ml}, 1,800 \mathrm{ml}$, and $150 \mathrm{ml}$, respectively.

The patient was transferred to the intensive care unit (ICU) while intubated because her respiration was not sufficient to remove the endotracheal tube, despite the reversal of neuromuscular block with pyridostigmine $20 \mathrm{mg}$. On arrival at the ICU, her blood pressure and heart rate were 83/35 $\mathrm{mmHg}$ and 124 beats/min, respectively. Then, the patient received a continuous infusion of norepinephrine at a rate of $0.05-0.2 \mu \mathrm{g} / \mathrm{kg} / \mathrm{min}$ in addition to dopamine and thereby the blood pressure increased to $105 / 52 \mathrm{mmHg}$. An arterial line was placed into the right dorsalis pedis artery to continuously monitor blood pressure and to collect blood samples. The blood gas analysis was as follows: $\mathrm{pH}, 7.32 ; \mathrm{PaCO}_{2}, 36.2 \mathrm{mmHg}$; $\mathrm{PaO}_{2}, 62.0 \mathrm{mmHg}$; and $\mathrm{O}_{2}$ saturation, $91.2 \%$. At that time, the pulse oximetry reading was $90 \%$ on mechanical ventilation, which was set in the synchronized intermittent mandatory ventilation mode using the following parameters: tidal volume, $500 \mathrm{ml}$; and respiratory rate, 8 breaths/min with a $\mathrm{FiO}_{2}$ of 1.0 without positive end-expiratory pressure support. Chest x-ray and computed tomography (CT) obtained at the completion of surgery showed no evidence of pulmonary edema or embolism. The infusion of dopamine and norepinephrine was discontinued the night of surgery because the hemodynamics had been stabilized. She regained consciousness 4 hours after cessation of anesthetics, but was still drowsy, agitated, and nauseated despite of the absence of lesions in the brain CT. It was 
Table 1. Perioperative Changes of Arterial Blood Gas Data and Electrolytes

\begin{tabular}{|c|c|c|c|c|c|c|c|c|}
\hline Time & $\mathrm{FiO}_{2}$ & $\mathrm{pH}$ & $\begin{array}{c}\mathrm{PaCO}_{2} \\
(\mathrm{mmHg})\end{array}$ & $\begin{array}{c}\mathrm{PaO}_{2} \\
(\mathrm{mmHg})\end{array}$ & $\begin{array}{c}\mathrm{HCO}_{3} \\
(\mathrm{mmol} / \mathrm{L})\end{array}$ & $\begin{array}{c}\mathrm{O}_{2} \text { sat } \\
(\%)\end{array}$ & $\begin{array}{c}\mathrm{Na}^{+} \\
(\mathrm{mmol} / \mathrm{L})\end{array}$ & $\begin{array}{c}\mathrm{K}^{+} \\
(\mathrm{mmol} / \mathrm{L})\end{array}$ \\
\hline Preop & - & - & - & - & - & - & 135.3 & 4.1 \\
\hline End & - & - & - & - & - & - & 118.0 & 3.9 \\
\hline $1 \mathrm{~h}$ & 1.0 & 7.32 & 36.2 & 62.0 & 19.1 & 91.2 & 120.3 & 3.9 \\
\hline $4 \mathrm{~h}$ & 1.0 & 7.38 & 27.7 & 84.1 & 16.1 & 95.3 & 123.1 & 3.7 \\
\hline $12 \mathrm{~h}$ & 1.0 & 7.47 & 25.9 & 184.4 & 19.2 & 99.2 & 129.7 & 3.4 \\
\hline $24 \mathrm{~h}$ & 0.6 & 7.46 & 31.1 & 98.9 & 22.3 & 98.0 & 133.2 & 3.8 \\
\hline $48 \mathrm{~h}$ & - & - & - & - & - & - & 136.0 & 4.1 \\
\hline $72 \mathrm{~h}$ & - & - & - & - & - & - & 137.8 & 3.9 \\
\hline
\end{tabular}

Preop: preoperative, End: end of surgery, $\mathrm{FiO}_{2}$ : fraction of inspired oxygen, $\mathrm{PaCO}_{2}$ : arterial carbon-dioxide pressure, $\mathrm{PaO}$ : arterial oxygen pressure, $\mathrm{HCO}_{3}$ : bicarbonate, $\mathrm{O}_{2}$ sat: arterial oxygen saturation.

not until the next morning that she was fully awake and welloriented. The $\mathrm{Na}^{+}$concentration measured 1 and 4 hours after surgery increased to 120.3 and $123.1 \mathrm{mmol} / \mathrm{L}$, respectively. The last supplemental dose of lasix (10 mg) was given intravenously. The arterial blood gas data were gradually improved over time (Table 1), and thus extubated the day following surgery. The $\mathrm{Na}^{+}$ concentration gradually returned to the normal range 24 hours after the surgery (Table 1). She was transferred to the general ward without any problems after a 3 day ICU stay.

\section{Discussion}

The patient presented herein had severe hypotension and water intoxication caused by an inadvertent large bolus injection of oxytocin instead of a continuous infusion. This mistake was made by an inexperienced assistant nurse in the process of taking order from the anesthesiologist. To avoid iatrogenic medication errors, it is suggested that anesthesiologists supervise their assistants with vigilance and assistants confirm the order before they execute it.

Oxytocin is generally used in accordance with a protocol involving continuous infusion of diluted oxytocin (typically 10 $\mathrm{mU} / \mathrm{ml}$ ) at a rate of $1 \mathrm{mU} / \mathrm{min}$ initially, with dose increment of no greater than $1 \mathrm{mU} / \mathrm{min}$ every $30 \mathrm{~min}$ [6]. However, oxytocin causes cardiovascular effects [2] mainly due to a decrease in systemic vascular resistance, varying from sinus tachycardia, mild hypotension, ST changes to even cardiac arrest in compromised patient [3]. In addition, an antidiuretic hormonelike effect of oxytocin may lead to water intoxication which could be life-threatening. Woodhouse reported that infusion of 240 units of syntocinon mixed in electrolyte free water over 32 hours in a gravida led to comatose state for 24 hours [4]. In our case we experienced abrupt hemodynamic changes after an accidental injection of large bolus of oxytocin. The reduced blood pressure did not recover soon and lasted for about 6 hours, which is not consistent with previous reports $[1,2]$ and made us misdiagnosed the signs as AFE until we were aware of the medication error. Delayed recovery of blood pressure could not thoroughly explained by oxytocin overdose alone because of its short biologic half-life. Thus prolonged hypotension may have been contributed to combinations of oxytocin overdose and other factors such as unrecognized hypovolemia or anaphylactoid reaction to oxytocin, although the latter is less likely to be the cause of hypotension than former because she already had an experience of delivery without any problem, in which oxytocin was used.

A decrease of arterial oxygen saturation was also one of the factors that led us to confuse the signs with AFE. In hindsight the unexplained hypoxemia represented in this case is considered to be attributed to secretion, positional change and mainly the mechanical factors of obesity rather than an AFE because it was relatively well-managed with merely a change in the original position, tracheal suction, and bronchodilators. Obesity impairs respiratory function, mainly expiratory reserve volume and functional residual capacity which further decrease below $50 \%$ of the pre-operative values respectively under general anesthesia [7].

Another reason we did not exclude an AFE early during surgery was that we could not sample the blood for laboratory confirmation of a coagulopathy, which is considered to be essential for the clinical criteria of AFE [8], because she was morbidly obese. It would have been helpful for the early decision to rule out AFE if we had secured the intravenous or intra-arterial line before anesthetic induction. Thus, the central venous line in the beginning is recommended to manage a catastrophe if an obese patient is scheduled for surgery.

We could not confirm the diagnosis of AFE even until the revelation because this patient did not show typical clinical manifestations of AFE including coagulopathy, uterine atony, seizures, cardiac arrest and even pulmonary edema except for only sudden changes of hemodynamics and reduced oxygen saturation. In addition, the hemodynamic changes were not intractable and responded relatively well to treatment compared with the typical appearance of AFE. As a whole, it 
was not considered as AFE because not all of the signs were consistent with an AFE.

Water intoxication, a kind of acute hyponatremia, is characterized by confusion, lethargy, vomiting, convulsion, periods of violent behavior, coma, and death due to cerebral edema. It rarely occurs even when a large bolus of oxytocin is administered, unless a large quantity of electrolyte free water is administered [9]. Nevertheless, in our case water intoxication was developed with the use of isotonic and colloid solutions. It has been reported that the continuous infusion of oxytocin decreases free water clearance regardless of water load [10]. Thus $1 \mathrm{~L}$ of $5 \%$ dextrose water infused at delivery room before transfer to operating room might have contributed to water intoxication in this case.

The signs and symptoms of water intoxication depend not only on the serum sodium concentration, but on its rate of decrease [11]. A serum sodium concentration of $120 \mathrm{mmol} / \mathrm{L}$ may cause mild symptoms, including confusion or restlessness, while a serum sodium concentration below $110 \mathrm{mmol} / \mathrm{L}$ is associated with seizures or coma, which are associated with a high mortality rate and thus require immediate treatment [12]. Although, the water intoxication is confirmed by measuring the serum electrolyte concentrations, its occurrence might be neglected if signs and symptoms are mild or patients are under general anesthesia as in our case. Even after the end of anesthesia, the patient showed no abnormalities on a brain CT or neurologic signs, but only mild symptoms, including drowsiness, nausea, and delayed recovery of consciousness, although it has not been proven to be related to water intoxication. It would be very helpful for early detection of water intoxication if the patient had spinal or epidural block.

Treatment of water intoxication includes an immediate discontinuance of the infusion of oxytocin and free water. Electrolyte-free water should be replaced with isotonic saline, while improving excretion of free water with furosemide or mannitol may be helpful. Administration of hypertonic saline depends on the presence of the neurologic symptoms and should be used with great caution since rapid correction might be associated with neurologic sequela, such as central pontine myelinolysis [13]. Thus, it is generally recommended that correction should be kept at a rate $<12 \mathrm{mmol} / \mathrm{L}$ per 24 hours and $<18 \mathrm{mmol} / \mathrm{L}$ per 48 hours [14]. In our case, there were no suspicious symptoms or signs suggesting neurologic complications, as we corrected the serum sodium concentration as recommended [14].

In summary, we present herewith a morbidly obese patient who developed severe hypotension and water intoxication following an accidental intravenous bolus injection of large amount of oxytocin during cesarean section. An extreme vigilance for confirming drug before its injection is required to avoid unexpected medication errors.

\section{References}

1. Pinder AJ, Dresner M, Calow C, Shorten GD, O'Riordan J, Johnson R. Haemodynamic changes caused by oxytocin during caesarean section under spinal anaesthesia. Int J Obstet Anesth 2002; 11: 156-9.

2. Thomas JS, Koh SH, Cooper GM. Haemodynamic effects of oxytocin given as i.v. bolus or infusion on women undergoing Caesarean section. Br J Anaesth 2007; 98: 116-9.

3. Thomas TA, Cooper GM. Maternal deaths from anaesthesia. An extract from Why mothers die 1997-1999, the Confidential enquiries into maternal deaths in the United Kingdom. Br J Anaesth 2002; 89: 499-508.

4. Woodhouse DR. Water intoxication associated with high dose syntocinon infusion. Med J Aust 1980; 1: 34.

5. Gist RS, Stafford IP, Leibowitz AB, Beilin Y. Amniotic fluid embolism. Anesth Analg 2009; 108: 1599-602.

6. Parker KL, Schimmer BP. Pituitary hormones and their hypothalamic releasing factors. In: Goodman \& Gillman's the Pharmacological Basis of Therapeutics. 10th ed. Edited by Hardman JG, Limbird LE: USA, McGrow-Hill. 2001, p 1559.

7. Roizen MF, Fleisher LA. Anesthetic implications of concurrent diseases. In: Miller's Anesthesia. 6th ed. Edited by Miller RD: San Francisco, Elsevier Churchill Livingstone. 2005, p 1032.

8. Clark SL, Hankins GD, Dudley DA, Dildy GA, Porter TF. Amniotic fluid embolism: analysis of the national registry. Am J Obstet Gynecol 1995; 172: 1158-67.

9. Moen V, Irestedt L. Water intoxication following labour and surgery: blaming oxytocin - the easy way out? Acta Anaesthesiol Scand 2009; 53: 1226.

10. Saunders WG, Munsick RA. Antidiuretic potency of oxytocin in women post partum. Am J Obstet Gynecol 1966; 95: 5-11.

11. Prough DS, Wolf SW, Funston JS, Svensen CH. Acid-base, fluid and electrolytes. In: Clinical Anesthesia. 5th ed. Edited by Barash PG, Cullen BF, Stoelting PK: Philadelphia, Lippincott-Raven Publishers. 2006, p 189.

12. O'hara Jr JF, Cywinski JB, Monk TG. The renal system and anesthesia for urologic surgery. In: Clinical Anesthesia. 5th ed. Edited by Barash PG, Cullen BF, Stoelting PK: Philadelphia, Lippincott-Raven Publishers. 2006, p 1028.

13. Laureno R, Karp BI. Myelinolysis after correction of hyponatremia. Ann Intern Med 1997; 126: 57-62.

14. Sterns RH, Cappuccio JD, Silver SM, Cohen EP. Neurologic sequelae after treatment of severe hyponatremia: a multicenter perspective. J Am Soc Nephrol 1994; 4: 1522-30. 